\title{
A problemática brasiguaia e os dilemas da projeção regional brasileira
}

\author{
Fabio Luis Barbosa dos Santos \\ Universidade Federal de São Paulo (UNIFESP), São Paulo, Brasil. \\ Email: faboroso@gmail.com
}

\begin{abstract}
Resumo: Inscrita na intersecção entre a questão agrária e a afirmação da soberania do Paraguai, analisamos neste artigo a problemática dos brasiguaios, indicando os dilemas que sugere sobre a projetada influência regional brasileira. Inicialmente, comentamos a bibliografia sobre a problemática brasiguaia produzida no Brasil e no Paraguai, além de alguns trabalhos realizados em outros países. A seguir, delineamos o marco histórico em que ocorre a migração massiva de brasileiros em direção ao país vizinho. Em um terceiro momento, analisamos o impacto da expansão do cultivo da soja no Paraguai nos marcos de um modelo produtivo difundido por corporações transnacionais, processo acelerado nos anos 2000 e que acirra os conflitos no campo, inclusive envolvendo brasiguaios. Por fim, enunciamos elementos que indicam o apoio do Estado brasileiro à expansão regional do agronegócio sugerindo uma contradição da política exterior brasileira, uma vez que os brasiguaios constituem um dos grupos de poder que endossou a conspiração que destituiu o presidente Fernando Lugo em junho de 2012, processo que contrariou os desígnios da diplomacia brasileira.
\end{abstract}

Palavras-chave: Brasiguaio; Paraguai; agronegócio; Governo Lugo.

\section{La problemática brasiguaya y los dilemas de la proyección regional de Brasil ${ }^{1}$}

Resumen: Inscrita en la intersección entre la cuestión agraria y el reclamo de soberanía paraguaya, se analiza en este artículo el problema de los brasiguayos, con indicación de los dilemas que sugieren acerca de la proyectada influencia regional de Brasil. Inicialmente, se comenta la literatura sobre el tema brasiguayo producida en Brasil y Paraguay, además de algunos trabajos realizados en otros países. A continuación se describen los antecedentes históricos de la aparición de la migración masiva de los brasileños hacia el país vecino. En una tercera etapa, se analiza el impacto de la expansión del cultivo de soja en Paraguay en el marco de un modelo de producción difundido por las corporaciones transnacionales, proceso acelerado en la década de 2000 y que exacerba los conflictos en el campo, involucrando incluso brasiguaios. Por último, enunciamos elementos que indican el apoyo del Estado brasileño a la expansión regional agroindustrial, lo cual sugiere una contradicción de la política exterior de Brasil, ya que los brasiguayos constituyen uno de los grupos de poder que respaldaron la conspiración que derrocó al presidente Fernando Lugo en junio de 2012, proceso que contradice los designios de la diplomacia brasileña.

Palabras clave: Brasiguaiyo; Paraguay; agroindustria; Gobierno de Lugo. 


\title{
The Brasiguayo issue and the dilemmas of Brazilian regional projection
}

\begin{abstract}
In this article we focus on the "brasiguaios" issue, underlining the dilemmas that it poses to the projected Brazilian regional influence. We begin analyzing the literature on the matter produced in Brazil and Paraguay, as well as in some other countries. After that, we sketch the historical context in which massive Brazilian migration towards the neighboring country has occurred. Then we analyze the impact of the expansion of soybean culture in Paraguay, which has been accelerated in the 2000's, and is referred to a productive model spread by transnational corporations that has increased social conflicts in the rural area, also involving brasiguaios. To end, we present elements that point out to a Brazilian State policy that supports this regional expansion of agribusiness, a fact that suggests a contradiction in Brazilian international policy, considering that brasiguaios were among the powerful sectors that endorsed the conspiracy that shortened Fernando Lugo's mandate in June 2012, process that contradicts brazilian diplomacy.
\end{abstract}

Key words: Brasiguayo; Paraguay; agrobusiness; Lugo’s Government.

***

\section{Introdução}

Inscrita na intersecção entre a questão agrária e a afirmação da soberania do Paraguai, analisamos neste artigo a problemática dos brasiguaios, indicando os dilemas que sugere sobre a projetada influência regional brasileira. O texto está constituido por quatro seções. Inicialmente, comentamos a bibliografia sobre a problemática brasiguaia produzida no Brasil e no Paraguai, além de alguns trabalhos realizados em outros países. No Brasil, constatamos que a preocupação original referia-se aos trabalhadores rurais que retornavam ao Brasil expulsos do campo paraguaio, problemática que, nos anos 1990, cedeu lugar a trabalhos angulados por um viés cultural, em torno ao tema das migrações. No Paraguai, a questão é abordada principalmente no bojo da questão agrária, acompanhando o ressurgimento das lutas pela terra a partir do final da ditadura (1989). Mais recentemente, há uma profusão de pesquisas realizadas principalmente por organizações vinculadas aos movimentos camponeses, em um contexto de acirramento dos conflitos no campo provocado pela expansão do agronegócio.

A seguir, delineamos o marco histórico em que ocorre a migração massiva de brasileiros em direção ao país vizinho. Indicamos que a raiz da problemática brasiguaia está referida à confluência de dois vetores da história paraguaia independente: a questão agrária e a influência do Brasil sobre o país, ambos processos relacionados, em sua origem, ao desfecho da Guerra da Tríplice Aliança (1865-1870). Os antecedentes imediatos da constituição do chamado "espaço brasiguaio" estão relacionados à aproximação estratégica entre as ditaduras de ambos lados da fronteira, em um contexto no qual a convergência de interesses geopolíticos e econômicos resultou em projetos de interesse comum, dentre os quais a colonização da região fronteiriça. 
Em um terceiro momento, analisamos o impacto da expansão do cultivo da soja no Paraguai nos marcos de um modelo produtivo difundido por corporações trasnacionais, processo acelerado nos anos 2000 e que acirra os conflitos no campo, inclusive envolvendo brasiguaios. Analistas paraguaios apontam que as características da inserção brasiguaia no agronegócio acentuaria o descolamento entre esta atividade e os demais setores da economia nacional, sugerindo a caracterização do agronegócio como um enclave.

Por fim, enunciamos elementos que sugerem o apoio do Estado brasileiro à expansão regional do agronegócio, o que no caso específico do Paraguai, implica no fortalecimento do poder brasiguaio. Esta constatação indica condutas contraditórias da política regional brasileira, uma vez que os brasiguaios constituem um dos setores que se opõem não somente à reforma agrária, mas a qualquer esforço de disciplinamento das relações sociais no campo paraguaio, constituindo um dos grupos de poder que endossou a conspiração que destituiu o presidente Fernando Lugo em junho de 2012, processo que contrariou os desígnios da diplomacia brasileira.

\section{A problemática brasiguaia: bibliografia}

O emprego frequente do termo relacionado a conflitos que envolvem proprietários rurais de origem brasileira, popularizou em anos recentes uma espécie de sinédoque, na qual o neologismo "brasiguaio" tornou-se sinônimo de empresário da soja. E no entanto, embora não haja estatísticas precisas (Palau 2001; Fogel e Riquelme, 2005), a maioria dos emigrantes brasileiros não usufruem desta condição econômica no país vizinho. Ao contrário, a própria origem do termo "brasiguaio" está associada à afirmação de uma identidade social positiva entre sem-terra brasileiros, no contexto de uma reivindicação fundiária que consumou-se em princípio dos anos 1980 no município de Novo Mundo, no Mato Grosso do Sul (Sprandel 1992). Esta diferenciação é relevante para discernir entre os conflitos potenciais cuja natureza fundamental é de classe, como aqueles que envolvem o agronegócio, de outras manifestações apoiadas meramente em sentimentos xenófobos (Capriglioni, 2012).

Aparentemente, os primeiros estudos abordando os brasiguaios no Brasil foram produzidos nos marcos da atuação da Pastoral do Migrante nos anos 1980, em um contexto de proximidade entre setores progressistas da Igreja católica brasileira e as pressões populares por reforma agrária. Sugerido como uma identidade positiva que acentuasse o caráter itinerante de populações fronteiriças em busca de assentamento rural, o termo "brasiguaio" refere-se originalmente, portanto, a trabalhadores rurais semterra ${ }^{2}$.

No início dos anos 1990 publicaram-se diversos livros sobre o tema, geralmente de caráter jornalístico, abordando os brasiguaios como trabalhadores rurais lutando contra uma situação injusta na área de fronteira 
(Alves, 1990; Wagner, 1990; Cortêz, 1994). Neste contexto, em que associase o problema dos trabalhadores rurais brasiguaios aos desequilíbrios socioambientais decorrentes da construção de Itaipu, organizam-se uma série de seminários com esta temática, nos quais participam representantes dos governos, movimentos sociais e intelectuais de ambos países (BASE IS, 1995).

A partir deste decênio, observa-se um crescimento da produção relacionada aos brasiguaios no âmbito acadêmico. No entanto, em contraste com os trabalhos pioneiros, a conflituosidade social aparece deslocada a um segundo plano nestes estudos, predominando enfoques que privilegiam a problemática identitária associada à migração (Albuquerque, 2005; Albuquerque, 2009; Santa Bárbara, 2005ª Santos, 2004; Fiorentin, 2010; Ferrari, 2009; Zaar, 2001). Em paralelo, encontramos alguns trabalhos de caráter técnico, como o diagnóstico genérico da situação dos imigrantes brasileiros no Paraguai realizado por Palau (PALAU, 2001), além de textos de natureza político-econômica, referenciados na expansão da atuação do capital brasileiro vinculado ao agronegócio (Salim, 1994; Tiburcio, 2009; Figueredo \& Lovois, 2006; Dros, 2004).

No Paraguai, no contexto de pressão pelo fim da ditadura (19541989) nos anos 1980, observa-se uma notável expansão de trabalhos abordando a realidade rural (Rivarola, 1986; Keikel \& Palau, 1987; Arditi \& Rodríguez, 1987). É necessário ter em conta os efeitos do clima repressivo que, aliado à precariedade institucional do Estado nacional, obstaram a investigação social, acadêmica ou não. A Universidad Nacional de Asunción, por exemplo, não oferecia a carreira de sociologia (Riquelme, 2003). Especificamente, a imigração brasileira não é destacada como um problema social, em um contexto em que o foco da denúncia política, no que concerne ao Brasil, é a natureza do vínculo entre os Estados submetidos a ditaduras, do qual decorre a construção de Itaipu e a Operação Condor, entre outros. Um estudo excepcional neste contexto foi produzido pelo sociólogo inglês Andrew R. Nickson, resultado de um trabalho de campo realizado em fins dos anos 1970 na fronteira oriental do Paraguai, onde na época viviam cerca de 300 mil brasileiros. Dentre outros aspectos, Nickson detalha as facilidades para o assentamento dos imigrantes brasileiros vis-à-vis as dificuldades encontradas pelos trabalhadores paraguaios que embarcaram nos programas de colonização incentivados pela ditadura (Nickson, 1981).

A expansão do cultivo da soja nos decênios recentes tem motivado trabalhos em que o protagonismo dos empresários rurais brasileiros é progressivamente criticado, ao passo que multiplicam-se os conflitos decorrentes da expansão desta atividade. Um indício desta guinada é que, no informe produzido em 1996, intitulado "La agricultura paraguaya al promediar los 90”, os brasiguaios sequer são mencionados por Palau, quem nos últimos anos de vida dedicou-se intensamente ao tema (Palau, 2007). Também constatamos que, na pesquisa realizada por Quintin Riquelme 
analisando cerca de 50 conflitos agrários em dois departamentos paraguaios nos anos 1990, nos quais a presença brasileira não é preponderante, observam-se apenas dois conflitos envolvendo proprietários brasileiros (Riquelme, 2003). Alguns anos depois, Marcial Riquelme organizou com Ramón Fogel uma compilação sobre os efeitos socioambientais da produção de soja, principal atividade rural no país. O livro é vertebrado em torno ao tema dos brasiguaios, abordado direta ou indiretamente por todos os autores (Fogel \& Riquelme, 2005). Fogel por exemplo, pretende responder às seguintes perguntas, entre outras:

“•¿Cuáles son los mecanismos productores de pobreza asociados a la expansión de los sojeros brasileños (control territorial y desarraigo, desocupación, evasión impositiva, enfermedades por contaminación, etc.)?.

- ¿Cuál es la lógica, en el marco de integración del MERCOSUR, que asocia a empresarios brasileños a las grandes corporaciones biotecnológicas, y al propio estado brasileño?” (Fogel, 2006: 37).

Assim, a acelerada expansão da soja e os múltiplos conflitos socioambientais a que está associada provocou em anos recentes numerosas publicações abordando o protagonismo brasiguaio. Às questões de natureza de classe comuns ao agronegócio no continente, acrescenta-se na situação paraguaia o problema da internacionalização da propriedade do solo nacional e a especificidade do protagonismo brasiguaio (Glauser, 2009). Em alguns casos, denuncia-se a ingerência do Estado brasileiro na defesa dos proprietários rurais nacionais (Fogel, 2011), e em outros, associa-se a IIRSA a este suposto expansionismo brasileiro, que estaria vinculado a projetos de ampliação dos cultivos para exportação, principalmente de soja (Korol \& Palau, 2009).

Para entender os conflitos atuais envolvendo os brasiguaios na perspectiva da crítica social paraguaia contemporânea, é necessário referi-los à convergência entre a questão agrária paraguaia e à influência brasileira sobre o país, delineando uma problemática que se aguça nos marcos da expansão do cultivo da soja no cone sul.

\section{Questão agrária e presença brasileira no Paraguai}

A problemática brasiguaia está enraizada na confluência de dois vetores da história paraguaia independente: a questão agrária e a influência do Brasil sobre o país. Em uma perspectiva histórica, ambos fenômenos estão relacionados ao desenlace da Guerra da Tríplice Aliança (1865-1870), episódio decisivo na formação do Paraguai contemporâneo, e que incidiu nas relações sociais no campo assim como na inserção internacional do país. Em sua expressão presente, a constituição do poder brasiguaio remete à convergência de interesses econômicos e geopolíticos entre a ditadura comandada por Alfredo Stroessner (1954-1989) e a política externa brasileira no período. 
Embora a natureza das relações de produção prevalentes no Paraguai antes da Guerra da Tríplice Aliança seja um tema polêmico, no país e no exterior (Pastore, 1972; Rivarola, 2010; White, 1984; Pomer, 1981; Chiavenatto, 1988; Doratiotto, 2002; Maestri, 2009), prevalece entre os estudiosos da questão agrária uma leitura segundo a qual a guerra alterou drasticamente as relações de produção vigentes, assentadas em modos de vida de orientação camponesa, em uma circunstância em que predominava a propriedade estatal da terra e não havia uma oligarquia vinculada ao latifúndio - caso singular no continente. Segundo este enfoque, o desenlace da guerra abortou o percurso relativamente autônomo de formação do Estado paraguaio, que foi então incorporado à esfera de influência de seus vizinhos, principalmente da Argentina, por meio de uma conversão de sentido mercantil do uso da terra, que lastreou a formação de uma classe dirigente análoga à de outros países da região, além da massiva aquisição de terras por estrangeiros (Fogel, 1998; Fogel, 2006; Rojas, 2009; BASE IS, 2010; Alderete \& Navarro Ibarra, 2009; Palau, 2012).

Do ponto de vista das relações com o Brasil, há um relativo consenso historiográfico assinalando uma mudança na orientação da política externa paraguaia a partir do regime instalado por Alfredo Stroessner (19541989), que se acercaria progressivamente do país em detrimento da Argentina (Moraes, 2001). Indica-se uma ingerência estadunidense no golpe operado em 1954, visando prevenir uma indesejada aproximação em curso entre o presidente paraguaio Frederico Chaves e seu colega argentino Juan Domigo Perón (Mello, 2002). Nos anos seguintes, o estabelecimento de uma rota comercial ligando o Paraguai ao oceano Atlântico por meio do porto de Paranaguá (elidindo assim a dependência secular em relação à Buenos Aires); a construção da Ponte da Amizade entre Foz do Iguaçu e a nova cidade de Puerto Stroessner (atual Ciudad del Este), iniciada em 1956; o estabelecimento desta nova cidade como polo comercial orientado fundamentalmente ao mercado brasileiro; são indícios desta reorientação da política externa paraguaia, que encontrou eco nos interesses do Estado brasileiro naquele momento. Estes vínculos estreitaram-se com o golpe militar no Brasil, quando preocupações geopolíticas e econômicas aliaramse em projetos de interesse comum, como a colonização da região fronteiriça (a Marcha para o Oeste no caso brasileiro, e para leste no caso paraguaio), a construção da usina hidrelétrica de Itaipu e a cumplicidade em torno à repressão social, avalizada pela Operação Condor (Menezes, 1987; Laino, 1979).

No que tange especificamente à questão agrária, em 1963 a ditadura criou o IBR (Instituto de Bienestar Rural) e promulgou um Estatuto Agrario, sinalizando a intenção de expandir a fronteira agrícola, promovendo a colonização de áreas principalmente no oriente do país, com o duplo propósito de aliviar a pressão social na região central e prevenir o enraizamento de grupos guerrilheiros em regiões fronteiriças. Projetada como uma estratégia de desenvolvimento mercantil da agricultura paraguaia, a colonização promovida pelo IBR descaracterizou-se de seu propósito oficial de enraizar trabalhadores no campo, distribuindo áreas a favorecidos 
do regime e praticando um próspero comércio de terras originalmente destinadas à reforma agrária.

Ao longo dos anos 1970, esta política de colonização do leste paraguaio convergiu com a expansão da fronteira agrícola brasileira que desenraizava trabalhadores rurais de suas terras, movimento intensificado na região fronteiriça no contexto da construção da hidrelétrica de Itaipu. Motivado pelo baixo preço relativo das terras paraguaias, uma pressão fiscal inócua, e a permissividade do Estado em relação a temas legais, trabalhistas e ambientais, produziu-se um significativo fluxo de brasileiros através da fronteira. Ainda, os imigrantes encontravam condições favoráveis de crédito no novo país, onde o Banco Nacional de Fomento facilitava recursos oriundos do Banco Mundial e do BID, emprestando-os a juros de $13 \%$ com prazo de reembolso de oito anos, concedendo-se três anos para começar a pagar, enquanto no Brasil as taxas vigentes oscilavam entre $22 \%$ e 24\%, com prazo de cinco anos para reembolso e apenas um ano de carência. Nickson aponta que estes empréstimos beneficiaram sobretudo aos brasileiros, que compravam suas terras à vista, uma vez que a exigência de titulação definitiva da propriedade excluía do acesso ao crédito a maioria dos paraguaios, que parcelavam a aquisição dos lotes. Diante destes fatos, o investigador inglês sintetizou no começo dos anos 1980 o resultado da atuação do IBR:

En conclusión, existen muchas evidencias que sugieren que desde su formación, en 1963 el IBR ha funcionado de una manera que facilita la penetración de la agricultura capitalista en el Paraguay bajo el control brasilero. Su política de no expropiación de los latifundios existentes y su decisión de vender las tierras fiscales vírgenes de la región, contribuyeron a la transferencia posterior de la mayor parte de la RFO (región fronteriza oriental) a manos brasileras, dentro de un período poco mayor al de una década. Al mismo tiempo, al reproducir las condiciones de vida minifundiarias, y la inseguridad en la tenencia de la tierras entre los colonos paraguayos a su cargo, el IBR ha asegurado la disponibilidad de una fuerza laboral, barata y sumamente inestable, para satisfacer la demanda creciente de mano de otra por parte de una agricultura capitalista en auge, en una región que hasta hace muy poco años era, en su mayor parte, inhabitada (Nickson, 1981: 240).

Assim, a migração de proprietários e trabalhadores rurais brasileiros em um contexto de expansão da fronteira agrícola e das remoções causadas pelas obras de Itaipu convergiu com a política de colonização do oriente paraguaio impulsionada pelo regime. Este movimento socioeconômico respondia aos interesses geopolíticos de ambas ditaduras. Stroessner alinhou-se decididamente com o Brasil, estabelecendo a posição paraguaia como beneficiária subalterna do crescimento econômico do país vizinho, ao mesmo tempo em que comungava as ideias de povoamento e desenvolvimento territorial como política antisubversiva nos marcos da Guerra Fria. A ditadura brasileira, por sua vez, incentivava a ocupação da 
região limítrofe referenciada na noção de “fronteira viva” manejada por Golbery do Couto e Silva (Couto e Silva, 1967), entendendo que a área de influência do Estado estende-se ao território ocupado por seus cidadãos. Ao mesmo tempo, acordos oficiais envolvendo a hidrelétrica de Itaipu, ou arranjos tácitos estimulando a colonização do oriente paraguaio favoreciam não somente esta estratégia geopolítica, mas também interesses econômicos representados pelo Estado brasileiro.

A massiva penetração de produtores rurais brasileiros atraídos pelas oportunidades econômicas que vislumbraram no outro lado da fronteira foi um dos resultados desta confluência de interesses. É este movimento migratório que está na raiz da constituição do que o geógrafo francês Sylvaine Souchaud (2002) chamou de “espaço brasiguaio”- um território caracterizado pela predominância da língua, da cultura e do poder político e econômico brasileiro, em território paraguaio. Este é um fenômeno singular na medida em que os imigrantes discriminam os trabalhadores nativos, ecoando estereótipos veiculados pela própria classe dominante nacional: "La regla universal suele ser que el que llega es discriminado, en algunos lugares esa discriminación llega a límites increíbles. Pero en Paraguay resulta lo contrario: el que llega se apropia de lo que tenemos y nos discrimina a nosotros. Eso es único” Fogel, 2011). A hegemonia econômica local dos brasileiros, assentada no agronegócio, conforma uma espécie de poder paralelo face à debilidade do Estado paraguaio, que por sua vez, revela-se desinteressado ou incapaz de integrar estes imigrantes à sociedade nacional, cujo poder é reforçado pela eleição de vereadores e prefeitos em municípios em áreas em que a sua presença é dominante (Albuquerque, 2009). Em uma situação em que a maioria dos trabalhadores brasileiros continua indocumentada, fala português e assiste à Rede Globo, a impermeabilidade do poder brasiguaio à institucionalidade local é, na visão de alguns analistas, uma realidade reconhecida e endossada pela diplomacia brasileira (Fogel, 2005).

Uma dimensão central da problemática brasiguaia é que a ocupação do solo paraguaio protagonizada por brasileiros ao longo dos últimos decênios não esteve assentada exclusivamente em mecanismos de mercado, mas apoiou-se em práticas irregulares de distribuição de terras praticadas desde a ditadura, que estão na origem das chamadas tierras mal habidas. $\mathrm{O}$ clientelismo e a corrupção na gestão do patrimônio fundiário do país prosseguiram após a queda de Stroessner em 1989, no contexto da singular abertura democrática paraguaia, conduzida pelo mesmo partido que gerenciou a ditadura.

Ao longo destes decênios, os brasileiros envolveram-se com estas práticas irregulares por dois caminhos principais: negociando as terras apropriadas pelos favorecidos da ditadura, mas também adquirindo lotes distribuídos aos que seriam os genuínos beneficiários da colonização. Estas terras são denominadas derecheras, pois consistem na cessão do direito (derecho) de ocupação de um pedaço de terra concedido pelo Estado e que, portanto, não pode ser vendido. Como um agravante, brasileiros adquiriram 
terras na região fronteiriça, situação que o governo procurou regulamentar por meio de uma lei vigente desde 2005, que cria uma zona de segurança em que é proibida a propriedade de estrangeiros em um raio de 50 quilômetros da divisa internacional - iniciativa que, apesar de suas limitações (Glauser, 2009), é severamente criticada pelas classes dominantes do país (Programa, 2012). Por fim, face à precariedade da situação cadastral em uma realidade em que o Estado não dispõe de registros confiáveis sobre a titulação e a metragem das propriedades, há o caso das chamadas "tierras excedentes", nas quais a extensão das terras efetivamente apropriadas é maior do que registrado em título, muitas vezes de legitimidade questionável por si mesmo.

Fruto de um trabalho impulsionado pela Comisión de Verdad y Justicia, constituída em 2003, cujo intuito é apurar o legado da ditadura stronista em diferentes esferas, publicou-se recentemente uma extensa investigação mapeando as tierras mal habidas do país, analisando casos que se estendiam até este mesmo ano. $\mathrm{O}$ resultado apontou que, de um total de 12.229.594 hectares de terras distribuídas a pretexto de reforma agrária, $64,1 \%$ foram apropriadas ilegalmente, o que constitui cerca de $1 / 5$ da área do país, ou 1/3 da área agricultável. Assim, haveria 7.851.295 hectares de terras ilegalmente apropriadas e portanto, passíveis de serem expropriadas pelo governo (Comisión, 2008: 205). Uma lista com 3.336 nomes referidas a 4232 propriedades foi divulgada, encabeçada pelo próprio Stroessner e por Andrés Rodriguez, o militar que o derrubou.

Segundo o sociólogo Ramón Fogel, um dos responsáveis pela investigação, 90\% das tierras mal habidas estariam em posse de brasiguaios na atualidade (Programa, 2012: 24), o que é um indício do nível de cumplicidade de interesses entre os gestores da política paraguaia no período e a expansão brasiguaia. Esta solidariedade se projeta no presente, expressando-se como uma resistência intransigente a qualquer disciplinamento do agronegócio, para não dizer à reforma agrária como instrumento de democratização da sociedade paraguaia.

\section{A soja e os brasiguaios}

Embora a massiva presença brasileira em território paraguaio não seja um fenômeno recente, os conflitos envolvendo brasiguaios tem se multiplicado no contexto da expansão do cultivo da soja no último decênio, nos marcos de um modelo produtivo dominado por corporações transnacionais (Rulli, 2007). Estima-se que em 1973 a oleoginosa ocupava 40 mil hectares no país. Em 1996 a superfície plantada aproximava-se de 1 milhão de hectares. Com a introdução de sementes transgênicas no final do decênio, calcula-se que a fronteira da soja avançou em média 125 mil hectares por ano nas safras seguintes, alcançando 2,8 milhões de hectares no ciclo agrícola de 2010/11 (Palau, 2012: 33 e 347). Em 2012, as projeções da Monsanto apontam que se ultrapassará os 3 milhões de hectares plantados, embora as toneladas produzidas indiquem uma redução da produtividade (González, 2011). Neste período, o país manteve altas taxas 
de crescimento, rompendo com a letargia prevalente desde a construção de Itaipu: em 2010 por exemplo, o ritmo da expansão da economia paraguaia só ficou atrás do Catar. Atualmente, o Paraguai é o quarto exportador mundial de soja e o oitavo de carne bovina.

A expansão concomitante da soja e da pecuária em um contexto em que se esgotava a disponibilidade de terras do Estado (as chamadas "tierras fiscales”), acirrou as contradições entre o agronegócio e os modos de vida de orientação camponesa, além de causar devastação ambiental no oriente do país e no Chaco, onde encontra-se ameaçado por exemplo, um dos últimos grupos aborígenes que vive em isolamento voluntário no continente, os ayoreo (Informe IWGIA, sem data).

No caso específico da soja, produto responsável pela maior receita dentre as exportações paraguaias, sua expansão implica na adoção de um modelo de negócio associado a um pacote tecnológico promovido pelas corporações transnacionais, que determina a forma como se produz a commodity em questão. Como no Brasil, o mercado é dominado pela semente transgênica resistente ao herbicida Roundup (glifosato), ambos patenteados pela Monsanto. Este pacote tecnológico está atrelado à técnica do plantio direto, em que os processos de arar e limpar o solo são substituídos pela aplicação de produtos químicos, cuja eficácia exige o seu uso em quantidade crescente. A maior economia associada ao plantio direto é a redução de mão-de-obra empregada, calculada em duas pessoas por cada mil hectares por ano, em um modelo produtivo viável somente para o cultivo em grande escala. Esta intensificação da agricultura é comparada por alguns autores a “una agricultura extractivista, una minería en el suelo agrícola”, em uma realidade na qual "el paquete de la soja implica la descampesinización absoluta, se trata de una agricultura sin agricultores” (Rulli, 2007: 18-20). No outro polo do processo, transnacionais como Cargill, ADM e Bunge açambarcam e exportam a soja produzida, o que levou um autor a concluir que "en la práctica, los productores son solo un engrenaje entre el proceso de provisión y el acopio de la produción (...)” (Rojas, 2009: 73).

Os impactos socioambientais da expansão da soja no Paraguai são documentados e denunciados regularmente por organizações vinculadas aos movimentos camponeses e indígenas (Palau, 2007). As consequências registradas incluem: expropriação de pequenos produtores por meio de múltiplos mecanismos (Rulli, 2007: 192-6); graves danos à saúde e ao meio ambiente em função das fumigações de agrotóxicos (Benitez Leite \& Acosta, 2011); aumento do desemprego, do êxodo rural e da emigração; maior concentração da terra (BASE IS, 2010: 29); ameaça à soberania alimentar; avanço direto sobre áreas virgens, mas também indireto, como consequência do deslocamento da fronteira pecuária (BASE IS, 2010: 5); potencial desertificação do solo em função da siembra directa; contaminação do aquífero Guarani (Fogel, 2008). Neste contexto, a expansão do cultivo da soja enfrenta a resistência do conjunto de atores sociais identificados com a democratização das relações de produção no campo e a preservação do meio ambiente, e que se opõem ao avanço das corporações transnacionais. 
É notório o protagonismo de empresários rurais brasileiros na expansão do agronegócio no Paraguai. Embora não haja estatísticas precisas, Glauser (2009) cruzou dados oficiais do INDERT (Instituto Nacional de Desarrollo Rural y de la Tierra) com a intenção de estimar a quantidade de terras de propriedade estrangeira no país. Seu trabalho revela que cerca de $1 / 5$ das terras nacionais estão em mãos estrangeiras, dentre as quais cerca de $2 / 3$ pertencem a brasileiros, o que equivale a 4.792 .528 hectares. Uma vez que a área agricultável do país é calculada em 24 milhões de hectares, estima-se que os brasileiros possuem em torno de 1/5 das melhores terras, dentre as quais incluem-se cerca de $40 \%$ da área dedicada à soja no país. A apropriação de terras por estrangeiros em larga escala também foi denunciada recentemente na Argentina e na Bolívia, para citar exemplos na região (Klipphan \& Enz, 2006; Urioste, 2011), mas o papel singular que a reivindicação dos derrotados na Guerra da Tríplice Aliança teve para a afirmação do nacionalismo paraguaio torna a preponderância brasiguaia um tema particularmente sensível (Capdevilla, 2010), ainda que o núcleo dos conflitos registrados no país até o momento seja basicamente a luta pela terra.

Segundo analistas paraguaios, a especificidade da situação do país em relação a outros exportadores de soja da região radica na ínfima integração do agronegócio às demais cadeias produtivas nacionais, fenômeno acentuado pelas características da inserção brasiguaia. De um modo geral, a baixa pressão fiscal sobre o agronegócio (Mendez, 2011), que ainda se beneficia de um significativo subsídio ao combustível utilizado na lavoura (Fogel, 2005: 69), minimiza as possibilidades de intervenção estatal em um sentido redistributivo. A exportação de um alto percentual de soja em grão, inclusive para o Brasil, reduz o potencial dinamismo econômico derivado do processamento da commodity no país (BASE IS, 2010: 6). Como um agravante da situação, admite-se que a produção de soja comandada por brasiguaios envolve operações de contrabando em grande escala, principalmente através da fronteira seca em que sua presença é dominante (BASE IS, 2011: 12), impactando negativamente na arrecadação tributária e na balança comercial do país:

El referido ingreso irregular de equipos y maquinarias por parte de las nuevas empresas brasileñas, sin los controles pertinentes, se proyecta en el hecho que el Paraguay sea, conforme a registros de la Comisión Económica para América Latina (CEPAL), el país al que menos inversiones viene en el continente, considerando el período 1990-2003, registrándose incluso una desinversión en el 2002. En esta dinámica que podría calificarse como clandestina, los empresarios del Brasil, vienen con sus propias maquinarias, sus propios tractores que después, eventualmente los vuelven a llevar al Brasil, de modo que técnicamente no hay inversión. Los tributos irrisorios a la exportación también son evadidos, en parte por los sojeros, estimando algunas fuentes en un millón de toneladas la soja que salió de contrabando en la última campaña agrícola. (Fogel, 2005: 68). 
Considerando o caráter dos nexos estabelecidos entre os grandes proprietários brasiguaios com o espaço econômico paraguaio, no bojo de um negócio transnacional em que constituem uma engrenagem, somada à impermeabilidade de seus protagonistas às instituições sociais e culturais do país vizinho, analistas consideram que a produção da soja constitui uma modalidade de economia de enclave em território paraguaio (Fogel \& Riquelme, 2005). Neste sentido, Fogel indica que: “(...) debe resaltarse en el análisis de la expansión de los sojeros brasileños, la dinámica del espacio fronterizo centrada en el brasiguayo, que responde más a relaciones y pautas del Brasil del cual depende, que de relaciones internas a nuestro Estado nación (Paraguay)”. (Fogel, 2005: 97).

Os vínculos que unem o espaço econômico brasiguaio à dinâmica do agronegócio no Brasil são referendados por uma recente pesquisa intitulada "Los actores del agronegocio en Paraguay", em que Luis Rojas (2009) analisou uma amostra das principais empresas envolvidas com o setor no país. Enfatizando que "la columna vertebral del agronegocio en el país constituyen las corporaciones transnacionales (...) que determinan en última instancia qué y como se va a producir (...) ", Rojas descreve a atuação de outras nove empresas estrangeiras, dentre as quais três são brasileiras, além de analisar outras 28 empresas consideradas nacionais, sobre as quais conclui: "De las 28 empresas nombradas, al menos 14 son propiedad, total o parcialmente, de brasileños (o brasiguayos), lo que representa el 50\% de esta muestra de empresas locales" (Rojas, 2009: 52-3).

Ao revelar a massiça presença de brasileiros nas principais empresas que atuam no Paraguai conectadas às corporações transnacionais, a investigação indica que protagonistas do setor tem negócios em ambos lados da fronteira, sugerindo vínculos próximos entre os atores do agronegócio nos dois países, que não se resumem à esfera das transnacionais que vertebram a atividade. Uma decorrência desta constatação é que a afinidade entre os setores que pressionam em favor do agronegócio no Brasil e no Paraguai pode ir além do interesse comum, pois em muitos casos, trata-se das mesmas empresas e pessoas. Diante desta realidade é plausível supor que, se o governo brasileiro mostrar-se suscetível às pressões do agronegócio em seu território, isto repercutirá no sentido da influência exercida em um país vizinho. Por exemplo, pode estimular sua expansão internacional por meio do BNDES ${ }^{3}$, como tem feito no campo da construção civil, apoiando estes interesses em uma região que pretende sob sua esfera de influência.

\section{República Unida de la Soja e o golpe a Lugo}

A multinacional do agronegocio Syngenta veiculou em 2003 uma peça publicitária em que desenhava-se uma "República Unida de la Soja”, abarcando territórios de Argentina, Bolívia, Brasil e Paraguai. As reações que despertou entre aqueles que se opõem à expansão da oleaginosa na região sugere que o anúncio dialogava com uma percepção generalizada 
sobre o poder das transnacionais do agronegócio, uma engrenagem produtiva que tem nos empresários dedicados à plantação a sua face mais visível (Rulli, 2007).

Elo mais fraco na cadeia do agronegócio em função da sua condição dependente, os proprietários rurais protagonizam os conflitos sociais decorrentes da privação de um meio de vida para a população camponesa, que a expansão da sua atividade implica. Na medida em que adquirem terras nos diversos países da região, sua atuação tende igualmente a transcender as fronteiras nacionais e como no caso das corporações a que se atrelam, contam com o apoio do aparelho estatal para assegurar o bom andamento de seus negócios. Isto pode significar, no caso de proprietários rurais de origem brasileira que expandem seus empreendimentos na direção do Paraguai e da Bolívia, a defesa dos seus interesses pela representação diplomática do Estado brasileiro, uma atuação sugerida pelos dois polos do problema: os empresários do agronegócio e aqueles que lutam pela reforma agrária. Nilson Medina, considerado o maior empresário rural brasileiro na Bolívia, refere-se a este apoio em uma entrevista:

Agora, nós, Heloisa, temos a garantia do governo brasileiro, sabe, eu acho que, assim como os "brasiguaios" têm a garantia do governo brasileiro, quando acontece alguma coisa lá existe uma intervenção, eu acredito que nós vamos ter a mesma atenção. $\mathrm{O}$ governo, o Celso Amorim, ele veio exclusivamente pra falar com a gente; o Celso Amorim, que eu acho um espetáculo o Celso Amorim, então, eu acho que, se acontecer alguma coisa aqui na Bolívia, o governo imediatamente vai intervir, e aí o Lula chama o Evo e fala: "Olha, a propriedade do Nilson Medina foi invadida, ele tem tudo certo, ele cumpre a função social e tudo...” (Gimenez, 2010).

Uma vez que o mais importante plantador de soja brasileiro na Bolívia evoca o exemplo dos brasiguaios como um precedente que afiança a sua situação sob o governo de Evo Morales, uma conjuntura certamente mais conflituosa do que o governo Lugo, infere-se que a atuação da diplomacia brasileira em defesa dos seus interesses é vista como um dado da realidade pelos empresários do setor. O mesmo Medina relata um episódio em que, durante a campanha presidencial de Morales, expressou ao então ministro da Agricultura do governo Lula, Roberto Rodrigues, preocupação em relação à possibilidade de desapropriação de brasileiros. Poucos dias depois o embaixador brasileiro no país teria telefonado para tranquilizar Medina, que mais tarde receberia garantias pessoais do próprio Morales ${ }^{4}$.

No outro lado do espectro político, ex-diretores dos órgãos encarregados de proceder à reforma agrária na Bolívia e no Paraguai, respectivamente sob Morales e Lugo, relatam pressões exercidas pela diplomacia brasileira em defesa do empresariado rural brasileiro ${ }^{5}$. Observadores da questão agrária no Paraguai também registraram uma intercessão recente no curso do conflito de terras em Ñacunday, episódio que explicitou os impasses enfrentados pelo governo Lugo em seu último ano. Tratava-se de 
terras de documentação frágil e procedência duvidosa em região limítrofe com o Brasil, apropriadas para a plantação de soja pelo ícone do poder brasiguaio no país, Tranquilo Favero (Capriglioni, 2012). Os acampados argumentavam que, além das suspeitas irregularidades na titulação, havia tierras excedentes, ou seja: a superfície abarcada pela propriedade seria superior à documentação registrada em pelo menos 12 mil hectares. Diante desta suspeita, o INDERT decidiu proceder à mensura do terreno, mas houve resistência dos brasiguaios. Com o respaldo de uma autorização judicial e de tropas, iniciaram-se os trabalhos mas, pouco depois, um segundo magistrado cassou o mandato original e o juiz que inicialmente o concedeu, foi punido. Neste contexto, observadores registraram a intervenção da diplomacia brasileira:

El gobierno de Brasil se interesó por el caso Ñacunday ante la inseguridad que podrían encontrarse las familias de brasiguayos. El interés del gobierno se manifestó en diversas acciones: el Cónsul adjunto del Brasil en Ciudad del Este, junto a abogados de productores y un asesor jurídico del Consulado brasileño, recorrieron la zona de Nacunday a fin de interiorizarse de la situación y el propio embajador de Brasil realizó una visita “de cortesía” al presidente del INDERT. (Programa, 2012: 5).

Ao final as terras não foram recuperadas, o INDERT sofreu intervenção do governo federal em meio a acusações de corrupção de seu terceiro diretor e os camponeses se retiraram, em um desfecho que referenda a observação de Fogel: “(...) nuestro Estado no ejerce control sobre la población de brasiguayos ni sobre sus bienes.” (Fogel, 2005: 69). Parte dos acampados de Nacunday transferiram-se à Curuguaty, palco dos trágicos eventos que serviram de pretexto para desencadear o julgamento de Lugo alguns meses depois.

Embora haja indícios convincentes de que a destituição do presidente foi precipitada por motivações políticas imediatistas (Santos, 2013), o poder brasiguaio é parte dos atores que confluíram com o interesse das multinacionais do agronegócio, da Rio Tinto Alcan, do Departamento de Estado dos Estados Unidos, de pecuaristas e traficantes diversos para favorecer a aliança tática entre liberais e colorados que consumou o golpe. Nesta perspectiva, o dilema paraguaio expressou um paradoxo da influência brasileira na região, na medida em que o apoio ao empresariado rural brasiguaio enrijeceu os óbices enfrentados pelo governo Lugo para avançar ações mínimas de democratização do acesso a terra, enfraquecendo sua posição diante de interesses que desencadearam um processo de impeachment que a diplomacia brasileira foi então, impotente para frear.

Neste contexto, a recomendação do Itamaraty de evitar sanções econômicas internacionais em reação ao golpe pode ser lida de maneiras distintas. Por um lado, temia-se mobilizar o nacionalismo paraguaio de característica irredentista, o que de todo modo ocorreu: a suspensão do país do Mercosul e o subsequente ingresso da Venezuela motivaram a denúncia, 
em tom histriônico, de uma suposta reedição da Tríplice Aliança (ABC, 2012a). Por outro lado, a alegação de que sanções econômicas trariam sofrimento ao povo paraguaio pode ser vista com cinismo, em uma circunstância em que o novo governo intensificará a repressão aos movimentos no campo e portanto, acentuará o drama dos trabalhadores rurais $^{6}$, enquanto os negócios prosseguem inabalados (ABC, 2012b).

Em um contexto em que prossegue a expansão da soja e da pecuária no Paraguai, a tensão social no campo tende a acirrar-se, e inscrita nesta problemática, os conflitos envolvendo brasiguaios. Embora algumas lideranças camponesas advoguem uma política classista, minimizando a importância da dimensão nacionalista da luta pela terra (Aguayo, 2012), o agravamento das condições de vida no campo face ao protagonismo brasileiro no agronegócio aguça a xenofobia entre os populares. Esta hostilidade é alimentada pelos próprios brasiguaios e seus aliados de classe, que veiculam preconceitos em relação ao trabalhador paraguaio, em contraposição a um suposto empreendedorismo brasileiro, necessário para o progresso do país (Souchaud, 2011).

Diante desta realidade, vislumbram-se reações em ao menos dois níveis: enquanto os movimentos sociais avançam uma crítica à influência regional brasileira que articula brasiguaios, agronegócio, Mercosul e IIRSA em uma perspectiva de classe, pairam sentimentos xenófobos suscetíveis de serem explorados sem mediações. É assim que a imprensa atribui ao obscuro EPP (Ejercito del Pueblo Paraguayo), pequeno agrupamento que pratica atos de banditismo social, o assassinato de um brasileiro que foi separado dos colegas paraguaios com que trabalhava no desmatamento de uma área rural pertencente a um brasiguaio, incidente registrado nas primeiras semanas da presidência de Frederico Franco (ABC, 2012c).

Associada à ditadura de Stroessner, às múltiplas ilegalidades que marcam a questão agrária no país, aos conflitos decorrentes da expansão do agronegócio e à intermitente ameaça brasileira à autonomia paraguaia, a questão dos brasiguaios problematiza a articulação entre as dimensões econômica e política da projeção regional brasileira: o agronegócio revelase como uma modalidade de expansão capitalista que combina violência socioambiental e dependência apoiada pela diplomacia brasileira, sinalizando que a soberania paraguaia subordina-se a uma razão de Estado solidária aos interesses da bancada rural em ambos países. Como resultado, potencia-se o crescimento econômico regional nos marcos de uma inserção internacional assentada na exportação de commodities, perpetuando as determinações fundamentais que obstam uma integração democrática e soberana. 


\section{Notas}

${ }^{1}$ Este artigo é resultado de investigação realizada no projeto "Estrutura Socioeconômica e Políticas para a Integração da América do Sul”, como pesquisador na área de "Conflitos territoriais e litígios potenciais na América do Sul" para a Diretoria de Estudos e Relações Econômicas e Políticas Internacionais do IPEA (Instituto de Pesquisa Econômica Aplicada), Brasil.

${ }^{2}$ Os primeiros textos produzidos por Marcia Anita Sprandel, que culminaram em sua dissertação de mestrado supra-citada, exemplificam esta abordagem.

3 “En mayo de 2007, la visita del Pdte. Lula en el marco del Seminario de Agrocombustibles Brasil-Paraguay, concluyó con la firma del memorándum de entendimiento. El presidente brasileño estuvo acompañado de 30 empresarios y los alentó a que invirtieran en el Paraguay. El Banco Nacional de Desarrollo Económico y Social (BNDES) de Brasil, anunció en dicho Seminario que contará con una línea de crédito específica para financiar a empresarios brasileños que decidan invertir en agronegocios en Paraguay.” (BASE IS. 2010, p. 10).

4 "Te conto que, uma vez, houve um rumor de que o então candidato a presidente Evo Morales ia desapropriar as propriedades dos brasileiros. Houve um rumor. Inclusive, ele chegou em Santa Cruz, e chegou a falar isso, isso saiu na mídia. E, o ministro Roberto Rodrigues, esteve em Santa Cruz, mais ou menos nessa ocasião, e foi uma preocupação minha até, eu falei com o ministro, e o ministro falou "olha, segundafeira eu tenho uma reunião com o presidente Lula e eu vou levar na minha agenda e vou conversar com o presidente Lula”, e o embaixador estava presente também, o embaixador na época era o Antonino Mendes, que está em Estocolmo na Suécia, hoje. O atual embaixador é Frederico Araújo, agora. Então, na segunda-feira, o então ministro Roberto Rodrigues, levou o problema para o presidente Lula e comentou com o presidente Lula que o então candidato Evo Morales havia falado isso. Bom, a resposta veio imediatamente, por meio do Roberto Rodrigues, embaixada, o embaixador me chamou pessoalmente pelo celular e falou: "Medina, o problema está contornado, o Lula já falou com o Evo, e está tudo certo, fica tranquilo”, e depois ele falou pra mim "Eu espero que ele cumpra..." (risos). Eu ri muito porque o embaixador é muito brincalhão, né, mas é a forma dele falar né. E então, o então candidato, Evo Morales, esteve em Santa Cruz nessa ocasião, e eu fui falar com ele. Eu fui lá e falei: "Escuta, como é que é, diz que você vai nos desapropriar, nos mandar embora?”, e ele respondeu: “Não, que nada, isso é a versão da mídia, não tem nada a ver...”. (GIMENEZ, 2010, anexo).

${ }^{5}$ Para o relato de Alcides Vadillo, ex-diretor do INRA (Instituto Nacional da Reforma Agraria), consultar o anexo da dissertação de Heloísa Gimenez citada. Alberto Alderete, ex-diretor do INDERT no Paraguai, afirmou com clareza que sofreu pressões do governo brasileiro durante sua gestão em entrevista ao autor em agosto de 2012.

${ }^{6}$ Tendência sinalizada ainda sob o governo Lugo. Consumada a chacina de Curuguaty, o então presidente substituiu o ministro do Interior, Carlos Filizzola, por Rúben Candia Amarilla, um colorado de notórios vínculos com o stronismo e detestado pelos movimentos sociais por sua atuação como fiscal general del Estado. Uma vez empossado, o primeiro anúncio do novo ministro foi decretar o final do "protocolo" estabelecido 
para lidar com ocupações de terra, que previa o diálogo inicial com os manifestantes. Ao nomear um colorado como ministro, Lugo incorreu no desprezo da esquerda ao mesmo em que aprofundou o fosso que o separava dos liberais, sua base de sustentação no parlamento 


\section{Bibliografía}

\section{Entrevistas realizadas em Assunção entre 31/7/2012 e 4/8/2012:}

Alberto Alderete. Ex-Diretor do INDERT (Instituto Nacional de Desarrollo Rural y de la Tierra).

Andrés Wehrle. Ex- Vice-ministro de Agricultura y Ganadería.

Idilio Méndez Grimaldi. Jornalista e economista.

Juan Díaz Bordenave. Membro do Consejo Nacional de Educación y Cultura.

Luis Aguayo. Dirigente da MNOC (Mesa Nacional de las Organizaciones Campesinas)

Luis Rojas Villagra. Coordenador BASE IS e pesquisador.

Miguel Lovera. Ex-Diretor do SENAVE (Servicio Nacional de Calidad y Sanidad Vegetal y de Semillas).

Milda Rivarola. Engenheira agrônoma e historiadora.

Quintín Riquelme. Sociólogo.

Ramón Fogel. Sociólogo.

Victor Jacinto-Flecha. Sociólogo.

\section{Obras consultadas}

ABC Color Digital (2012a), Paraguay denuncia otra triple Alianza. Assunção, 26/6/2012. Disponível em: http://www.abc.com.py/nacionales/ denuncian-otra-triple-alianza-contra-paraguay-419073.html. Acesso em 18/ 8/2012.

Ídem (2012b), 'Brasiguayos' pedirán a Itamaraty que respalde a Franco. Assunção, 24/6/2012. http://www.abc.com.py/edicion-impresa/politica/ brasiguayos-pediran-que-itamaraty--respalde-a-franco-418087.html. Acesso em $15 / 8 / 2012$

Ídem (2012c), Ejecutan brasileño y queman tres topadoras en estancia en Ajot’y.' Assunção, 30/6/2012. Disponível em: http://www.abc.com.py/ edicion-impresa/judiciales-y-policiales/ejecutan-a---brasileno-y-quemantres-topadoras-en--estancia-de-azotey-420573.html. Acesso em 14/8/2012.

Albuquerque, J. L. C (2005), Fronteiras em movimento e identidades nacionais. A imigração brasileira no Paraguai. Fortaleza, 2005. Tese 
(Doutorado) - Programa de Pós-Graduação em Sociologia, Universidade Federal do Ceará.

Ídem (2009), “A dinâmica das fronteiras: deslocamento e circulação dos "brasiguaios" entre os limites nacionais”. Horiz. antropol. [online]. vol.15, n.31 [cited 2012-02-23], pp. 137-166.

Alderete, Luciano \& Navarro Ibarra, Liliana (2009), Paraguay en la encrucijada: movimiento campesino y governabilidad durante el periodo 19892008. Disponível em: http://paraguay.sociales.uba.ar/files/2011/08/ P_navarro_alderete_2009.pdf. Acesso em: 18/5/2012.

Alves, J. L. (1990), Brasiguaios: destino incerto. Global, São Paulo.

Arditti, Benjamín; Rodríguez, José Carlos (1987), La sociedad a pesar del Estado. Movimientos sociales y recuperación democrática en el Paraguay. CDE, Asunción.

BASE IS (2010), Los impactos socioambientales de la soya en Paraguay. Base IS, Asunción.

Ídem (1995), Brasiguayos, Itaipu y Mercosur. Memorias del IV seminario binacional sobre brasiguayos. Documento de Trabajo 68. Disponível em: http://www.portalguarani.com/detalles_museos_otras_ obras.php?id=87\&id_obras=1981\&id_otras=295. Acesso em 18/5/2012.

Batista, L. C (2010), Brasiguaios na fronteira: caminhos e lutas pela liberdade. Dissertação (Mestrado) - Faculdade de Filosofia, Letras e Ciências Humanas, Universidade de São Paulo, São Paulo.

Benitez Leite, Stela; Macchi, Maria Luisa; Acosta, Marta (2007), Malformaciones congenitas asociadas a agrotoxicos. Assunção: BASE IS, 2011; Palau, Tomas et. al. Los refugiados del modelo agroexportador. Impacto del monocultivo de soya en las comunidades campesinas paraguayas. Base IS, 2007, Asunción.

Capriglioni, Laura (2012), “Conflito com brasiguaio não é diplomático, e sim, agrário”. Folha de São Paulo, 20/12/2012.

Ceceña, Ana Ester; Aguilar, Paula; Motto, Paulo (2007), IIRSA: territorialidad de la dominación. Observatorio Latinoamericano de Geopolitica, Buenos Aires.

Chiavenatto, J. J. (1988), O genocídio americano: a guerra do Paraguai. Brasiliense, São Paulo.

Comisión de Justicia y Verdad (2008), Informe Final de la Comisión de Verdad y Justicia. Tomo IV: Tierras Mal Habidas. Comisión de Justicia y Verdad, Asunción. Disponível em:http://www.meves.org.py. Acesso em 20/3/2012. 
Cortêz, C (1994), Brasiguaios: os refugiados desconhecidos. s. l.. Brasil Agora.

Couto e Silva, G. (1967), Geopolítica do Brasil. 2 a edição, Livraria José Olympio Editora, Rio de Janeiro.

Doratiotto, F. (2002), Maldita Guerra- nova história da Guerra do Paraguai. Cia. das Letras, São Paulo.

Dros, Jan Marteen (2004), Managing the boom: two scenarios of soy production expansion in South America. AIDEnvironment. Amsterdam.

Ferrari, C. A. (2009), Dinâmica Territorial na(s) fronteira(s): um estudo sobre a expansão do agronegócio e a exploração dos brasiguaios no norte do departamento de Alto Paraná - Paraguai. Dissertação de Mestrado. Universidade Federal da Grande Dourados (UFGD).

Figurredo, O. A. T.; LOVOIS, A. M. (2006), A modernização da agricultura e os brasiguaios no Paraguai. Disponível em: http://www.sober.org.br/ palestra/5/970.pdf, Acesso em 15/2/2012.

Fiorentin, M. I. (2010), A experiência da imigração de agricultores brasileiros no Paraguai (1970-2010). Dissertação de Mestrado apresentada ao Programa de Pós-Graduação em História da Universidade Federal do Paraná.

Fogel, Ramón (2008), “La región de la triple frontera: territorios de integración y desintegración”. Sociologias n’.20 Porto Alegre.

Ídem Riquelme Marcial (2005), Enclave sojero: merma de soberania y pobreza. Ceri, Asunción.

Ídem (1988), “Tierra y democracia: la lucha de los campesinos paraguayos”. Nueva Sociedad, n. 96, p. 163-173.

Ídem (2006), Movimientos campesinos y su orientación democrática en el Paraguay. Compilador/es: Hubert C. de Grammont (En publicación): “La construcción de la democracia en el campo latinoamericano”. CLACSO, Buenos Aires.

Ídem (2011), Entrevista concedida a Fatima Rodriguez para o periódio E’A, em 25/07/2011. Disponível em: http://ea.com.py/ramon-foguel-este-es-elunico-pais-donde-los-inmigrantes-son-los-que-discriminan-a-los-locales/ Acesso em 10/4/2012.

Glauser, Marcos (2009), Extranjerización del territorio paraguayo. BASE IS, Asunción.

Gimenez, Heloisa Marques (2010), O desenvolvimento da cadeia produtiva 
da soja na Bolívia e a presença brasileira: uma história incomum. Dissertação de mestrado apresentada no PROLAM-USP, São Paulo.

González, D (2011), “Paraguay por primera vez superará 3 millones de hectáreas en soja.” Assunção: 5 dias, 30/8/2011. Disponível em: http:// www.5dias.com.py/5310-paraguay-por-primera-vez-superar-3-millonesde-hectreas-en-soja. Acesso em: 15/8/2012.

Grain (2008), ¡Se adueñan de la tierra! El proceso de acaparamiento agrario por seguridad alimentaria y de negocios en 2008, Documentos de análisis.

Informe IWGIA (sem data), El caso Ayoreo. Paraguai.

Korol, Claudia; Palau, Marielle (2009), Resistencias populares y recolonización del continente. Talleres de la triple frontera. Base IS, Asunción.

Ídem (2009), “IIRSA: o futuro do continente como mercadoria”. Em: Korol, Claudia; Palau, Marielle. Resistencias populares y recolonización del continente. Talleres de la triple frontera. Base IS: 69-74, Asunción.

Keikel, M. V.; Palau, Tomas (1987), Los Campesinos, el Estado y las Empresas en la frontera agrícola. BASE ISEC, PISPAL, Asunción.

Klipphan, A.; Enz, D. (2006), Tierras S/A. Cronicas de un pais rematado. Alfaguara, Buenos Aires.

Laino, D (1979), Paraguai: fronteiras e penetração brasileira. Global, São Paulo.

Maestri, M (2009), “A Guerra Contra o Paraguai: História e Historiografia: Da instauração à restauração historiográfica [1871-2002]”. Estudios Históricos - CDHRP- N 2 - ISSN: 1688 - 5317.

Marques, M. E. C. M. (1995), A Guerra do Paraguai - 130 anos depois. Relume- Dumará, Rio de Janeiro.

Mendez, I. (2011), Monsanto golpea en Paraguay: Los muertos de Curuguaty y el juicio político a Lugo. Disponível em: http:// www.atilioboron.com.ar/2012/06/por-que-derrocaron-lugo.html. Acesso em 5/8/2012.

Mello, Leonel Itaussu Almeida (2002), Brasil e Argentina em perspectiva. Rev. hist., São Paulo, n. 147. Disponível em http://www.revistasusp.sibi. usp.br/scielo.php?script=sci_arttext\&pid=S0034-

Menezes, A. (1987), A herança de Stroessner : Brasil - Paraguai, 19551980. Papirus, São Paulo. 
Moraes, C. (2001), "Interesse e colabroação do Brasil e dos Estados Unidos com a ditadura de Stroessner (1954-63)”. Diálogos, v. 11, n. 1 e 2, p. 55-80.

Nickson, A. R. (1981), "Brazilian colonization of the Eastern Border Region of Paraguay”, Journal of Latin American Studies n. 13 (maio de 1981), Republicado como: “Colonización brasileña de la región oriental del Paraguay”. Em: Fogel, Ramón; Riquelme, Marcial (2005), Enclave soyero merma de soberanía y pobreza. CERIS: 219-239, Assunción.

Palau, Tomas (2012), Es logico que una sociedad agredida se defienda. BASE IS, Asunção.

Ídem (2001), “Brasiguaios”. In: Migrações Internacionais - Contribuições para políticas. CNPD, Brasília.

Ídem (2005), “El movimiento campesino en el Paraguay: conflictos planteamientos y desafíos”. Em: OSAL (Observatório Social de América Latina. Año 6, n.16 (jun 2005). Clacso, Buenos Aires.

Ídem et. al. (2007), Los refugiados del modelo agroexportador. Impacto del monocultivo de soya en las comunidades campesinas paraguayas. Base IS, Asunción.

Pastore, C. (1972), La Lucha por la tierra en el Paraguay. Editorial Antequera, Montevideo.

Pomer, L (1981), A guerra do Paraguai: a grande tragédia rioplatense. Global, São Paulo.

Programa Democratización y Construcción de la Paz (2012), Monitoreo de la Política de Reforma Agraria del Gobierno Lugo. Síntesis a Diciembre 2011. Asunción.

Riquelme, Q. (2003), Los sin tierra en Paraguay. Conflictos agrarios y movimiento campesino. Clacso, Septiembre, Buenos Aires.

Rivarola, D. (editor) (1986), Los movimientos sociales en el Paraguay. CPES, Asunción.

Rivarola, Milda (2010), Vagos, pobres y soldados - La domesticación estatal del trabajo en el Paraguay del siglo XIX. Servilibro, Asunción.

Rojas, L. (2009), Actores del agronegocio en Paraguay. Base IS/ Diakonia, Asunción.

Rulli, J. (2007), Republicas unidas de la soya. GRR, Cordoba. Disponível em: http://lasojamata.iskra.net/es/republicasunidas. Acesso em 10/4/2012. 
Santa Bárbara, M. (2005ª), Des-caminhos brasileiros em terras paraguaias. Dissertação (Mestrado) - Departamento de Geografia, Universidade Federal Fluminense, Rio de Janeiro.

Ídem (2005), “Brasiguaios: território e logos de identidades”. In: Neto, H. P.; Ferreira, A. P (Org.) Cruzando fronteiras disciplinares - Um panorama dos estudos migratórios. Revan, 2005b, Rio de Janeiro

Salim, C. (1994), "Migración brasiguayos y MERCOSUR. Fuerza de trabajo rural en el centro-oeste brasilero". En publicacion: Migración brasiguayos y MERCOSUR. Fuerza de trabajo rural en el centro-oeste brasilero. BASE-IS, Asuncion.

Santos (2013), F. L. B. “A destituição de Lugo e os limites da democracia na América Latina”. Brazilian Journal of Latin American Studies. PROLAM, São Paulo.

Santos, M. E. P (2004), O cenário multilíngüe/multidialetal de fronteira e o processo identitário de alunos brasiguaios no contexto escolar. Tese (Doutorado) - Instituto de Estudos da Linguagem, Universidade Estadual de Campinas, Campinas.

Souchaud, S (2001), Nouveaux espace en Amerique du Sud: la frontière Paraguayo-Brésilienne. Mappemonde, ps. 19-23.

Ídem (2002), Pionniers brésiliens au Paraguay. Kaethala, Paris.

Ídem, Carmo, Roberto Luiz do; Fusco, Wilson (2007), Mobilidade populacional e migração no Mercosul: a fronteira do Brasil com Bolívia e Paraguai. Teoria \& Pesquisa, VOL XVI, n.1, jan-jun 2007.

Ídem (2011), A visão do Paraguai no Brasil. Contexto int. vol.33 no.1, Jan./June, Rio de Janeiro.

Sprandel, M. A. (1992), Brasiguaios: conflito e identidade em fronteiras internacionais. Dissertação (Mestrado) - PPGAS, Museu Nacional, Rio de Janeiro.

Ídem (2006), Brasileiros na fronteira com o Paraguai. Estud. av., São Paulo, v. 20, n. 57.

Tiburcio, J. (2009), Brazilians in Paraguay: A Growing Internal Problem or a Regional Issue? Paper presented at the annual meeting of the ISA ABRI JOINT INTERNATIONAL MEETING, Pontifical Catholic University, Rio de Janeiro Campus (PUC-Rio), Brazil, Jul 22, 2009, Rio de Janeiro.

Urioste, M. (2011), Concentración y estrangerización de la tierra en Bolívia. Fundación Tierra, La Paz. 
Polis, Revista Latinoamericana, Volumen 13, $N^{\circ}$ 38, 2014

Wagner, C. (1990), Brasiguaios: homens sem pátria. Vozes, Petrópolis. Ídem (2003), País-bandido: crime tipo exportação. RBN, Porto Alegre.

White, Richard Alan (1984), La primera revolución radical de America (1811-1840). La Republica, Asunción.

Zaar, Miriam H. (2001), “A Migração Rural No Oeste Paranaense / Brasil: A Trajetória Dos "Brasiguaios"”, Scripta Nova. Vol. 88, No. 94, p. 2.

Recibido: 22.09.2014

Aceptado: 20.11.2014 